\title{
En Bloc Removal of the Mandible, the Trigeminal Muscles and the Mandibular Nerve in Humans
}

\author{
M.A. Aziz ${ }^{1}$, K. Lashley ${ }^{1}$ and R. Diogo ${ }^{*}, 2$ \\ ${ }^{I}$ Department of Anatomy, Howard University, College of Medicine, 520 W Street, N.W., Washington, DC 20059, USA \\ ${ }^{2}$ Center for the Advanced Study of Hominid Paleobiology, Department of Anthropology, George Washington University, \\ 2110 G Street, N.W., Washington, DC 20052, USA
}

\begin{abstract}
The trigeminal nerve supplied muscles share many traits due to their common embryological derivation from the mandibular branchial arch. Many of these muscles, especially the masticatory, exhibit very complex intra- and intermuscular anatomical and functional specializations which continue to be investigated. Two schemes have been proposed to classify the intramuscular and extramuscular slips associated with these muscles: 1) based on recognizable laminae within each muscle; 2) based on the pattern of nerve distribution to definable parts of each muscle. The extramuscular slips have been identified on the bases of their nerve supply. The second scheme is beginning to yield results which confirm Edgeworth's $(1914,1935)$ hypothesis regarding the ontogeny and phylogeny of the trigeminal nerve supplied musculature. These advances in the rational classification of these muscles have resulted from improved methods to expose the deeper parts of the masticatory and related spaces. However, because of the piecemeal exposure of parts of the spaces which contain some of the deeper trigeminal muscles there remain several issues that still need to be resolved. We provide a detailed protocol by which all the trigeminal nerve supplied muscles can be isolated from the upper cranium so that the entire mandibular nerve tree along with its musculature may be described as a connected complex of related structures. The practical and clinical implications of this new methodology are evaluated and discussed.
\end{abstract}

Keywords: Trigeminal musculature, mandibular arch derivatives, mandibular nerve, En bloc dissection method, ontogeny, phylogeny.

\section{INTRODUCTION}

The trigeminal nerve $(\mathrm{CN} \mathrm{V})$ is the largest cranial nerve of the head region. It has three divisions: ophthalmic $\left(\mathrm{V}_{1}\right.$; general sensory afferent, GSA); maxillary $\left(\mathrm{V}_{2} ; \mathrm{GSA}\right)$, and mandibular $\left(\mathrm{V}_{3}\right.$; GSA and special visceral efferent, SVE; e.g., $[1,2]$. The maxillary and mandibular nerves innervate critical parts of the stomatognathic system; the mandibular nerve exclusively supplies all principal masticatory muscles which occupy large parts of the head, bilaterally. Warwick and Williams [1, p. 1004] write that "in view of the fact that the mouth is generally regarded as representing a pair of fused visceral clefts, the maxillary nerve can be described as the pretrematic and mandibular nerve as the post-trematic branch of the trigeminal nerve".

In addition to the masticatory muscles (temporalis, masseter, lateral and medial pterygoids), branches of the mandibular nerve also supply the mylohyoid and the anterior digastric muscles which play supplementary roles during the masticatory cycle. Additionally, branches of the mandibular nerve supply a muscle of the soft palate (tensor veli palatini) and an otic muscle (tensor tympani).

*Address correspondence to this author at the Center for the Advanced Study of Hominid Paleobiology, Department of Anthropology, George Washington University, 2110 G Street, N.W., Washington, DC 20052, USA; Tel: 001-202-994-6075; Fax: 001-202-994-6097;

E-mail: RuiVDiogo@hotmail.com
All muscles which receive branches of the mandibular nerve are proximately derived from the mandibular (first) branchial arch myological plate; the ultimate source of the cells programmed to form these muscles is Somitomere no. 4 [3]. According to Edgeworth's magisterial ontogenetic and phylogenetic studies only some of these "mandibular arch" muscles (masseter, temporalis, lateral pterygoid; tensor veli palatini, tensor tympani; medial pterygoid) are derived from the adductor mandibulae of plesiomorphic vertebrates; for instance, the mylohyoid and the anterior digastric are derived from "the intermandibularis muscle", i.e. a muscle of the ventral region of the mandibular plate [4-8].

As far back as 1914 Edgeworth (based on comparative myological and embryological studies of various vertebrate taxa) proposed that the mammalian masticatory muscles be classified in accordance with their positions in relation to the main stump of the mandibular nerve [7]. Thus, one closelyrelated cluster of muscles - the masseter, temporalis and the lateral pterygoid - is located lateral to the main stump of the mandibular nerve (and are supplied by the branches of the mandibular nerve which originate on its outer, i.e. lateral, aspect) while the medial pterygoid (which receives a branch originating from the medial aspect of the main nerve) represents a distinct separate myogenetic pathway from the mandibular muscle plate.

In a major revision of the classification of the masticatory muscles, Tomo $[9,10]$ added the tensor tympani and the 
tensor veli palatini, to the muscle mass which formed the medial pterygoid. Following Tomo's [9] rational reclassification of the masticatory (and related) muscles, Shimokawa and his associates $[11,12]$ and Akita and his coworkers $[13,14]$ undertook a major revision of the subparts of the masseter, the temporalis and lateral pterygoid muscles based on their nerve supply. The major aims of these investigations included: 1) an objective reclassification of these "complicated masticatory muscles" [15]; Tomo et al. [10] referred to the temporalis and the masseter each as "muscles"]; 2) to establish the true affinities of muscle slips such as the zygomatico-mandibularis, the pterygoid proprius (Henle), etc.; 3) to establish the true relationships of muscle slips which are attached to the TMJ disc; 4) to elucidate the reasons accounting for the relative positional closeness of certain masticatory muscles to each other in comparison to others, and 5) to use the trajectories of the branches of the mandibular nerve to postulate the migration patterns of the populations of myocytes which formed these muscles.

In over a century and a half since the publication of Gray's Anatomy [16], morphologists have endeavored to access and comprehend the functional anatomy of the components of the deep masticatory space with incremental success. The following methods have been described: 1) the lateral approach [16-19]; 2) the medial approach [20-27]; 3) the superior approach [28-30]; 4) the posterior approach [31, 32] and 5) lateral pterygoidectomy (see [33] for a review of this and other approaches). Collectively, these methods have constituted a collage of the deep masticatory space; however, these efforts have amounted to less than a sum of its individual parts. It has not always been easy to connect them into an organic, integrated framework [9-14].

The objective of this report is to provide a detailed protocol by which the human mandible may be detached from the rest of the human skull along with all the trigeminal nerve supplied musculature [34] except the tensor tympani (our future efforts will endeavor to extract this muscle as well). The necessity and advantages of this en bloc method will be discussed.

\section{MATERIAL AND METHODS}

The human head (Specimen \#HU 01; Fig. 1A, B) used in this research was obtained from the Willed Cadaver Donation Program for the Training of Health Care Professionals at Howard University College of Medicine, Washington, D.C. This project was undertaken to develop high quality prosections for instruction in head and neck anatomy for freshmen students of medicine and (especially) dentistry. The superficial dissection of facial muscles on this specimen was done by freshmen students of dentistry; the rest of the head was available for further work on the masticatory muscles and their neurovascular structures. The specimen was hemisected to extract the brain which was used in the neuroanatomy instruction program; thus, the entire cranial cavity including the trigeminal nerve was available for further observations.

All specimens used for the preliminary osteological investigations were obtained from the Osteological Collection housed in the Human Anatomy Laboratory, Department of Anatomy, Howard University College of Medicine.
In addition to the traditional dissecting instruments commonly used in the gross anatomy laboratory, the following tools were essential to achieve optimal results: stryker saw; fluorescent magnifier lamp (1.75x); Hu-Friedy hard wire cutter (or any similar bone cutter); Blumenthal 30 rongeur, and - important - the periosteal elevator (Hu-Friedy \#9 molt ). At critical phases the dissection process was halted to permit photography, hand drawings, and note taking. The same dissection was performed on both sides.

After the removal of the mandible, the masticatory muscles and their nerves and vessels, further dissection was conducted under the fluorescent magnifying lamp using several microsurgical instruments, such as microscalpels, microscissors, the pin probe, and dissection pins. The magnifying lamp is essential to facilitate the clearer exposure of the finer nerves and vessels that are located deep to the lateral pterygoid heads. The following areas were studied in detail: 1) the middle cranial fossa; 2) the skull base; 3 ) the lateral skull; and 4) the mandibular ramus.

\section{RESULTS}

The en bloc removal of the mandible, the masticatory muscles, the mandibular nerve (and its branches), the maxillary artery (and its branches), and the maxillary vein (and its tributaries) was achieved in the following sequential steps:

Step 1: The zygomaticus major and minor, the platysma and the associated facial muscles and their fasciae were mobilized by dissection and reflected in the rostral direction. The outer surfaces of the zygoma and the zygomatic arch were exposed by removing all the fasciae and the periosteal membrane; cleaning was extended all the way posteriorly as close to the external auditory meatus as possible. The parotid duct and the buccal nerves (CN VII) were exposed as they coursed below the zygomatic arch. These were cut close to their origin from the parotid gland; they, too, were reflected in the same direction as the facial muscles and fasciae described above. The temporal fascia was detached from the temporalis (the superior part of which had mostly been removed during the craniotomy), and dissected down to its attachment along the zygomatic bone and arch. This fascia was cut and removed.

Step 2: The borders of the parotid gland were more clearly defined by the removal of the binding connective tissue along the borders. The gland was pried away from the masseter and lifted up along its anterior border and reflected rostrodorsally towards the ear. It was lifted clear of its attachment along the posterior margin of the mandibular ramus. Thus, the retromandibular fossa/space was exposed. The glandular tissue in the area just below the temporomandibular joint (TMJ) was teased up in order to expose the auriculotemporal nerve, the external carotid artery (and its branches: the maxillary and the superficial temporal arteries), and the retromandibular vein (and its tributaries: the maxillary vein and the superficial temporal vein). 


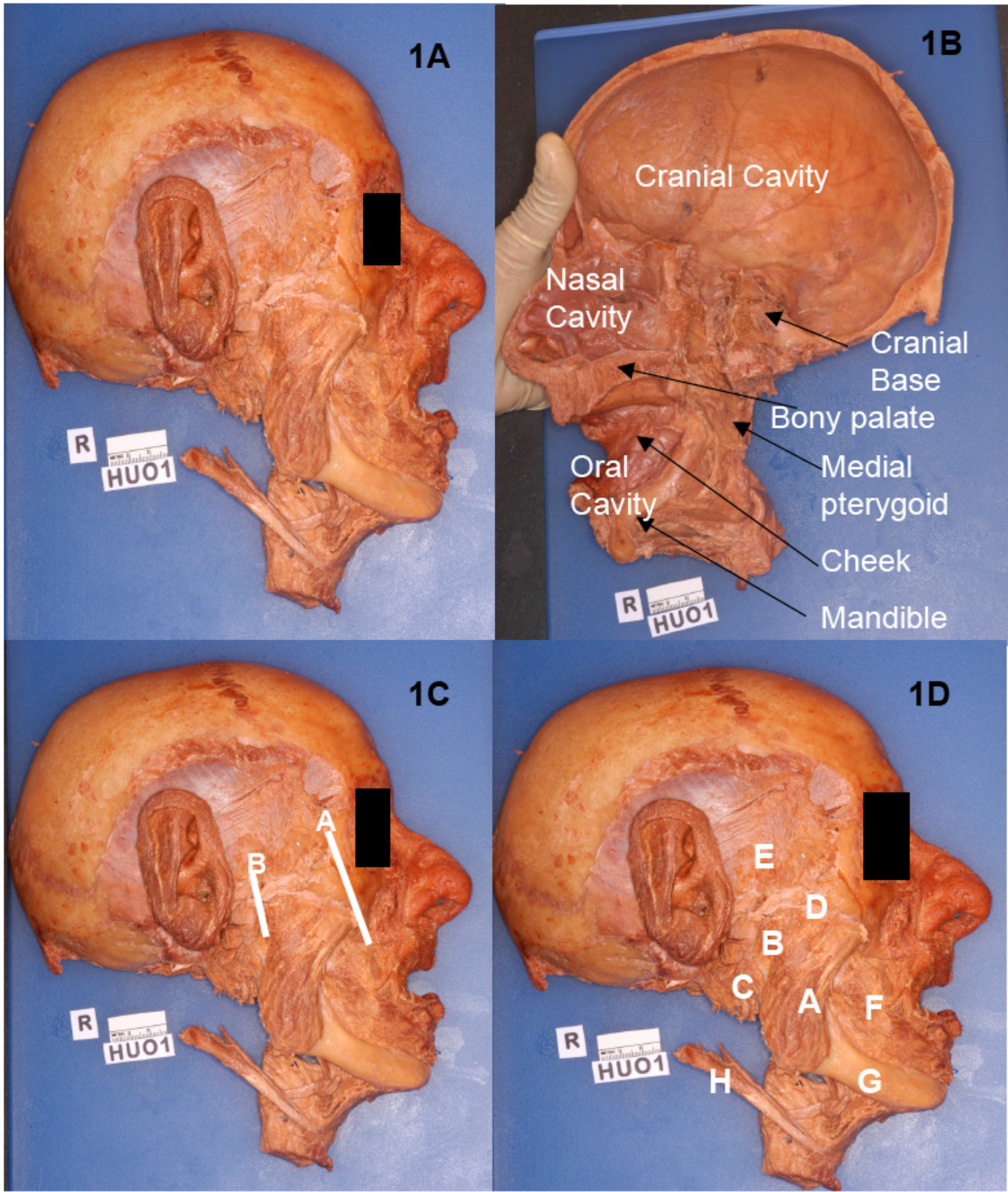

Fig. (1). A) Specimen HU O1, the outer aspect of the right half head. B) Specimen HU O1, the medial aspect of the right half head. C) Specimen HU O1, lines of osteotomy to mobilize the zygomatic arch. D) Specimen HU O1, significant bones and muscles on the lateral aspect of the specimen, showing the superficial part of the masseter (A), the deep part of the masseter (B), the parotid gland (C), the zygomatic arch (D), the temporalis muscle and fascia $(\mathbf{E})$, the buccinator muscle $(\mathbf{F})$, the mandibular body $(\mathbf{G})$ and the posterior belly of the digastric $(\mathbf{H})$.

Step 3: The auricle of the ear was excised close to its attachment to the outer, cartilaginous margins of the external auditory meatus. Thus, the TMJ's external surface, with its capsule, and ligament were now revealed. The whole area was cleaned in order to better delineate these structures; cleaning was extended to the posterior aspect of the joint. The membranous "stylomandibular" 
ligament was found inserting on the posterior aspect of the mandibular ramus, just above the mandibular angle.

Step 4: The external surface of the masseter was cleaned and its borders defined. Using the spatulate end of the periosteal elevator, the muscle was detached from its insertion on the outer aspect of the mandibular ramus. This detachment was continued towards the zygomatic arch. The muscle was lifted, and by gentle teasing in the area close to the (over the mandibular notch) TMJ, the masseteric nerve, artery and vein were located and defined as they divided and arborized in the muscle. The zygomatic arch was now mobilized by the following two cuts using the stryker saw: an oblique cut of the zygomatic bone and a cut of the zygomatic process of the temporal bone just anterior to the external auditory meatus (Fig. 1C, D). The zygomatic arch was pulled laterally to expose the deep masseter and the zygomaticomandibularis; some of the fibers of the zygomaticomandibularis were attached close to the temporalis tendon. In the vicinity of the TMJ, the deep masseter and the temporalis appeared to be continuous.

Step 5: The temporalis was mobilized from the temporal fossa by using the spatulate end of the periosteal elevator. This process was extended all the way to the posterior margin of the frontal process of the zygomatic. Muscle detachment was continued as far inferiorly and caudally as possible. The anterior deep temporal artery and its branches could be seen after the fatty tissue ("corpus adiposum buccae") covering the anterior margin of the zygomaticomandibularis was cleaned. The temporalis was pulled laterally to expose the anterior deep temporal artery as it coursed anterosuperiorly towards the border of the zygomaticomandibularis. The lower part of the temporalis in the vicinity of the infratemporal crest of the greater wing of the sphenoid was teased to expose the deep temporal nerves which were accompanied by the branches of the posterior deep temporal artery.

Step 6: The hemi-section was now turned over to expose its medial aspect. The medial pterygoid's superficial surface was cleaned and its boundaries delineated.

Step 7: The soft palate was cut and removed. This exposed the rostro-superior aspect of medial pterygoid. It also exposed the tensor veli palatini which was located in the pterygoid fossa. The medial pterygoid was detached from its insertion on the medial aspect of the mandibular ramus. The muscle was mobilized along its posterior border. As this process was extended rostro-superiorly, the mylohyoid nerve and vessels could be seen attached to the deep/external aspect of the medial pterygoid. This neurovascular bundle was pried away from the muscle and laid on to the mandibular ramus. The muscle detachment was extended antero-superiorly to reveal the inferior alveolar neurovascular bundle as it entered the mandibular canal through the mandibular foramen. The spheno- mandibular ligament was clearly visible in this area. Further muscle mobilization in the rostral direction exposed the lingual nerve as it coursed toward the floor of the oral cavity; it traversed along the medial margin of the mandibular ramus and its body. It was accompanied by a lingual branch of the inferior alveolar artery.

Step 8: The tensor veli palatini was pried away from the medial pterygoid to reveal the nerve to the medial pterygoid. A smaller nerve, located immediately to its rostro-superior aspect, was seen feeding into the tensor veli palatini.

Step 9: The tensor veli palatini and the medial pterygoid were now detached from the pterygoid fossa. The pointed end of the periosteal retractor is an excellent tool to achieve this. Still, at some points, where the muscles were very strongly attached to the bone, the microscalpel was used to detach the muscle. The external part of the medial pterygoid was reflected by cutting along the external surface of the lateral pterygoid plate. This cut was extended upward to mobilize the origin of the inferior head of the lateral pterygoid muscle.

Step 10: The TMJ capsule on the medial aspect of the joint was now cleaned, exposed and cut horizontally. The cut was no more than $4 \mathrm{~mm}$ from the posterior margin. This limited cut prevented the excision of the main stump of the mandibular nerve as it emerged from the foramen ovale into the infratemporal fossa.

Step 11: The hemi-head was now turned to bring the internal floor of the basicranium (i.e. the view showing the cranial fossae) into full view. The dura mater was peeled away to expose the entire trigeminal nerve, its sensory ganglion, and its three divisions (ophthalmic, maxillary, and mandibular nerves). The entire nerve was cleaned and its borders defined. The nerve, its ganglion, and its divisions (ophthalmic, maxillary, and mandibular) were now peeled away from medial wall of the middle cranial fossa (greater wing of sphenoid). The ophthalmic and maxillary nerves were cut and freed in the immediate vicinity of their entry into the superior orbital fissure and the foramen rotundum, respectively.

Now, a wedge-cut pointing towards the foramen ovale (containing the mandibular division of the trigeminal nerve and other structures) was made from the surface using the stryker saw (Fig. 2). The anterior cut was made starting from the area close to the sphenoparietal eminence - the area close to the optic canal. The posterior cut began in the posterior cranial fossa and was continued through the petrous temporal bone towards the foramen ovale. In order to preserve the mandibular nerve in the foramen ovale; care was 
taken not to cut into it. Rather, the cuts reached close to the foramen in order to preserve the deep boundary of the opening. The trigeminal nerve was retracted laterally during the osteotomy to prevent damage to it. Now, using the pliers, the remaining bony wedge close to the foramen ovale was broken off. The rongeur was used to remove the remaining bone along the medial border of the foramen ovale; the area around the main stump of the mandibular nerve was cleaned to mobilize it along with vessels. The entire freed portion of the mandibular nerve (and the rest of the trigeminal nerve) were now pried out of the foramen ovale.

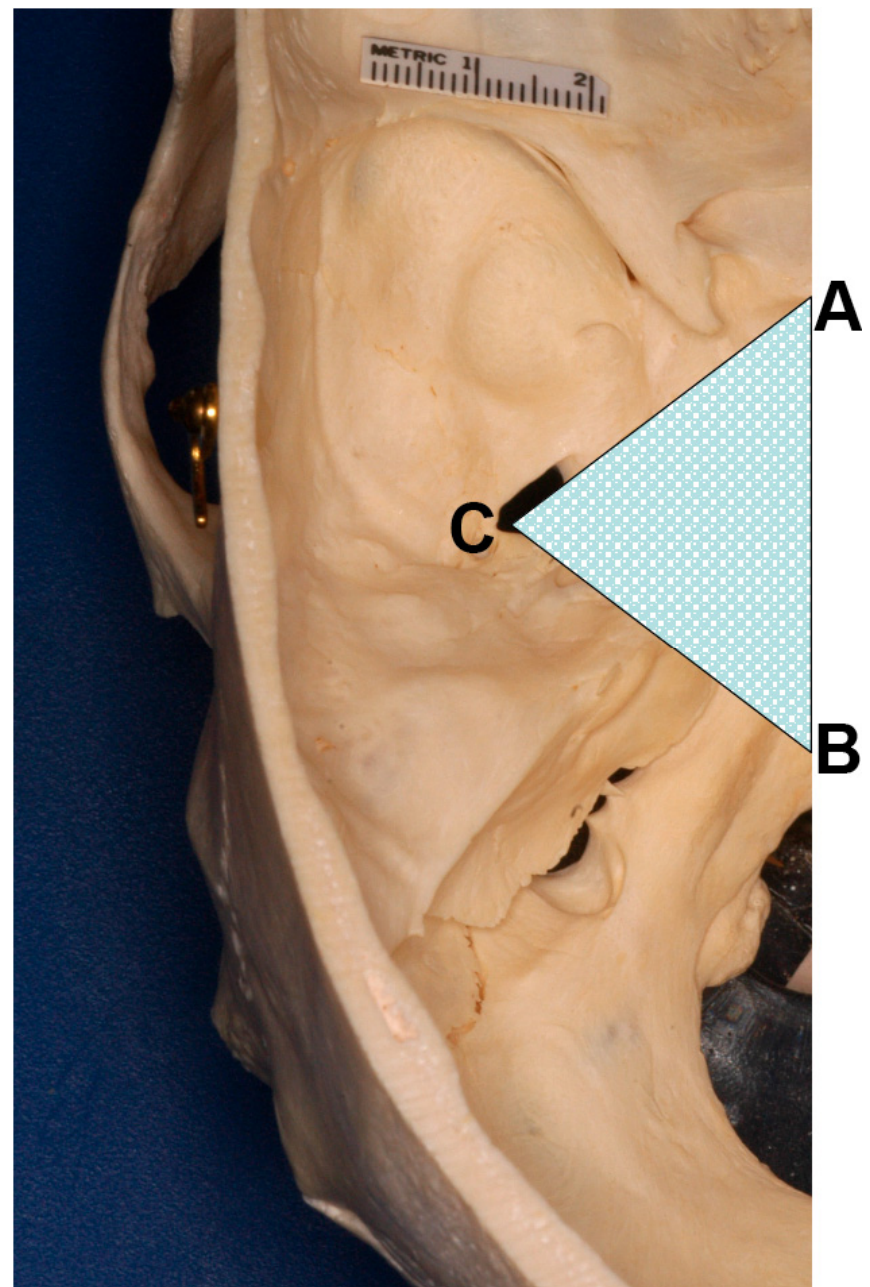

Fig. (2). Shape of the bony wedge removed to expose foramen ovale and its contents.

Step 12: The spatulate end of the periosteal retractor was inserted into the superior cavity of the TMJ. The cavity was opened by pushing the retractor caudally. This revealed the attached anterior part of the TMJ capsule. It was very carefully cut and the retractor was pushed forward and downward to peel the attachment of the superior lateral pterygoid from the infratemporal part of the greater wing of the sphenoid. The nerves to the masseter, the posterior and middle deep temporal nerves, and the (long) buccal nerve were separated out along with the superior pterygoid head.
Step 13: A cut was made from the posterior edge of the oral cavity to divide the cheek in order to free the mandible. A careful inspection was made of all sides to free all structures that still articulated / connected the mandible to the cranium. Now, using measured force (and ensuring that the stump of the mandibular was clearly out of the foramen ovale), the mandible was pried away from the cranium (Fig. 3).

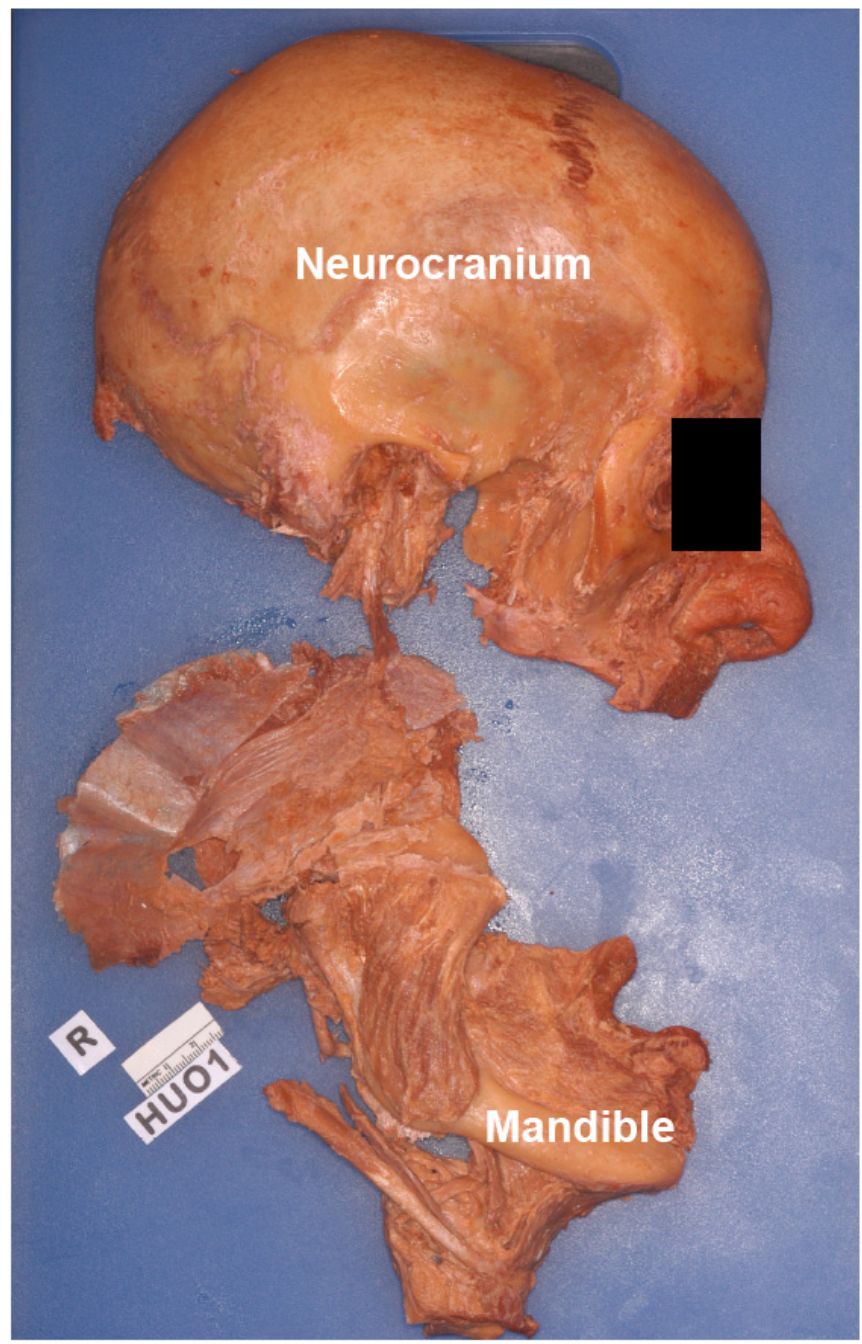

Fig. (3). Specimen HU O1, detached mandible along with its muscles.

Step 14: The entire mandible, its muscles, and neurovascular structures were cleaned by removing the covering fasciae. Following this the mandible was brought under the illuminated magnifier to extend the dissection to the finer structures of the entire complex (Figs. 4, 5).

\section{DISCUSSION}

Since the second half of the $19^{\text {th }}$ Century and early $20^{\text {th }}$ Century, two schemes of classifying the complex myological components of each masticatory muscle in mammals, including the derived primates (humans included), have been devised by investigators: 1) partition of an individual muscle based on the laminae distinguishable by separations formed by fascial sheaths or by silver-toned tendons (aponeuroses) 
or by tendinous septa ("laminar classification") and 2) the subdivision of each muscle based on its nerve supply from the mandibular nerve ("nerve supply classification") $[2,20$, $22,23,35-82]$.

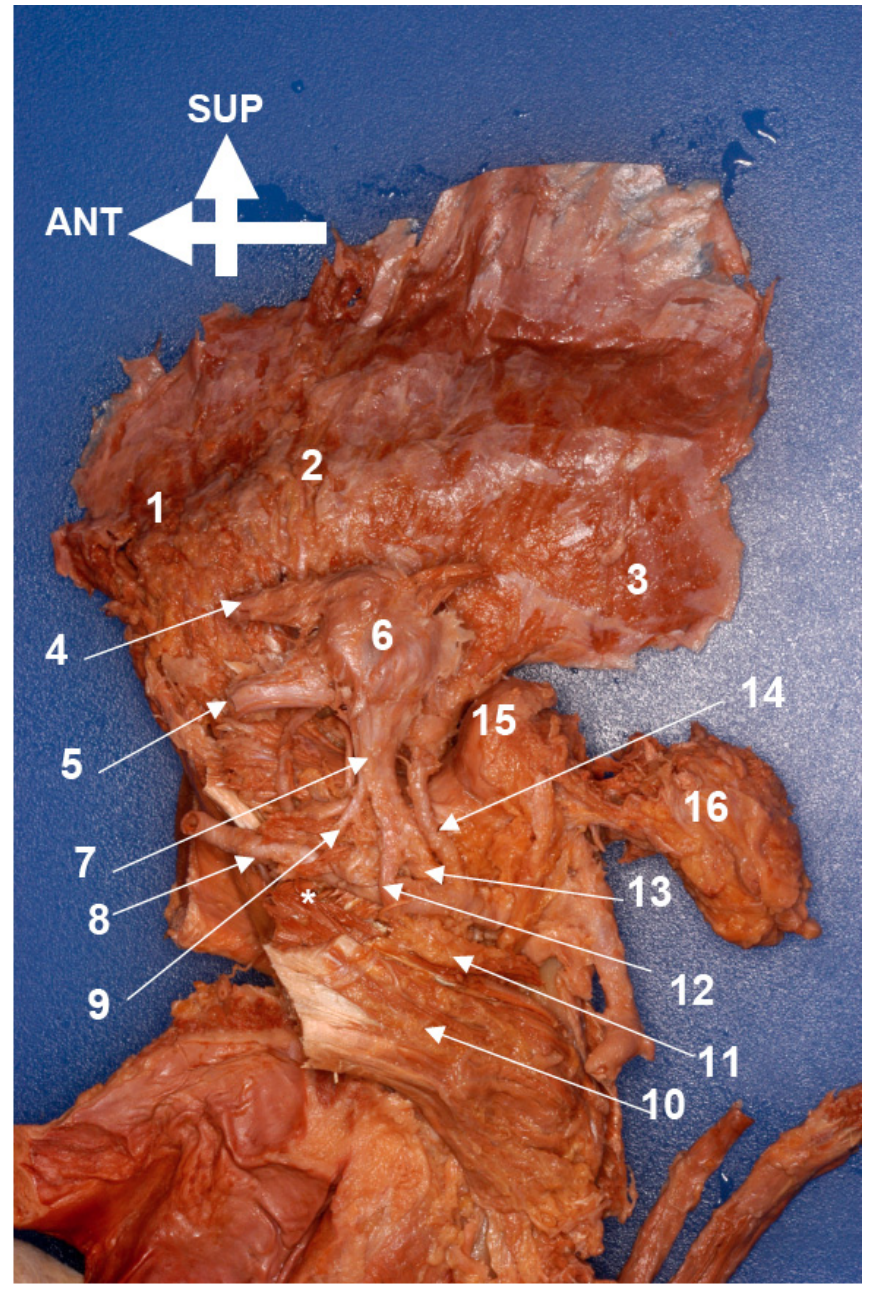

Fig. (4). Specimen HU O1, medial aspect of the masticatory muscles and the mandibular nerve complex, right block (*indicates the inferior belly of the lateral pterygoid muscle). 1, Temporalis (pars superficialis). 2, Temporalis (pars profunda, main portion). $\mathbf{3}$, Temporalis (pars profunda posterior). 4, Ophthalmic nerve (CN V1). 5, Maxillary nerve (CN V2). 6, Trigeminal ganglion. 7, Mandibular nerve (CN V3; main stump). 8, Maxillary artery (pterygoid section). 9, Buccal nerve. 10, Medial pterygoid muscle (main body). 11, Medial pterygoid muscle (upper part). 12, Lingual nerve. 13, Stump of inferior alveolar and auriculotemporal nerves. 14, Middle meningeal artery. 15, Head of condyle (covered by disc). 16, Parotid gland.

In the late 1940's Tomo revisited the laminar classification of the canid masticatory muscles as described by earlier investigators [83-85] and found many discrepancies in the information. His aim was to develop a more rational, reliable, and essentially reproducible and predictable classification of canid masticatory muscle using the nerve supply of each muscle as had been originally proposed by Toldt [59]. Luter [86, 87], Luter and Lubosch [88], and Lubosch [89-91] had already used this method to developed a more satisfactory subdivision and classification of the constituent parts of each masticatory muscle in fish, amphibians and reptiles. This method made full use of ontogenetic and phylogenetic information about the organisms which were studied. Edgeworth [7, 8] also used similar comparative morphological and developmental analyses to propose a grand scheme of classifying mammalian craniomandibular muscles.

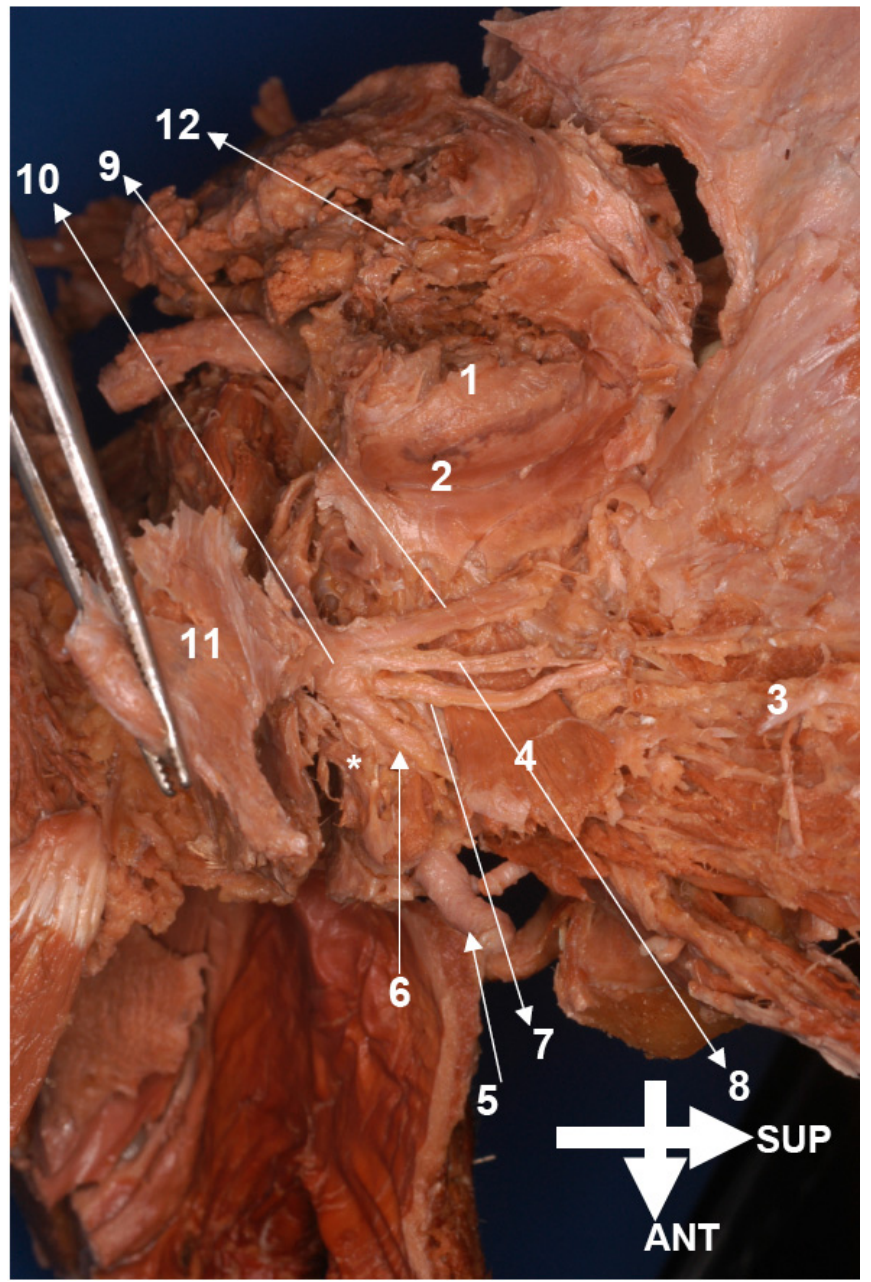

Fig. (5). Specimen HU O1, superior aspect of the masticatory muscles and the mandibular nerve complex, left block $(*$ indicates the inferior belly of the lateral pterygoid muscle). 1, Head of condyle covered by disc. 2, Disc-superior lateral pterygoid junction. 3, Temporalis (deeper aspect). 4, Superior lateral pterygoid (upper view). 5, Maxillary artery (pterygoid section). 6, Buccal nerve. 7, Middle deep temporal nerve. 8, Posterior deep temporal nerve. 9, Nerve to the masseter (main stump). 10, Superior division of mandibular nerve. 11, Trigeminal ganglion. 12, Parotid gland.

The term "trigeminusmuskulatur" was first coined by Schulman [34] to refer to the craniomandibular muscle complex which received branches of the mandibular nerve and which was responsible for the functioning of the craniomandibular articulation and related structures in the immediate vicinity. Such holistic approaches of organizing muscles supplied by the trigeminal nerve were also used by Luter [86], Lubosch [89] and Göllner [60], on various vertebrates (including the derived primates). Tomo inaugurated his reclassification of the dog's masticatory muscles by observing that "the methodology....involved careful removal of all bones from the muscles. Retaining the mandibular nerve..." [10]. For example, for a more detailed study of the dog's lateral pterygoid muscle, Tomo et al. [92] 
wrote that "the temporomandibular joints were decalcified" for sagittal sectioning and stained with methylene blue and fuchsin. Further refinement of the technique involved the preservation and acute observation of the mandibular nerve tree using a silicone permeation technique which facilitated "excellent localization of nerves innervating the muscle and (has) the added advantage of providing a three-dimensional structure of neural anatomy" [92].

Tomo et al. [10] proposed a clearer, logical reclassification of the canid masticatory muscles which illuminated intra- and interrelationships, both ontogenetic and phylogenetic. Analyses of the mandibular nerve tree was a crucial part of this success. In addition to providing credible tests of Edgeworth's [7, 8] hypotheses regarding the deeper bases of the organization of the masticatory muscles, Tomo et al. [10] convincingly demonstrated that the dog had distinct, named branches to the muscles: temporal, lateral pterygoid, and buccal (which forms several lateral pterygoid nerves and also gives of the anterior deep temporal nerve). These branches originated from the anterior trunk of the mandibular nerve. The posterior trunk is mainly sensory in nature; its motor branches supply selected muscles of the floor of the oral cavity (branches: lingual, inferior alveolar and the auriculotemporal nerve; the mylohyoid nerve is a branch of the inferior alveolar nerve). This pattern of branching of the proximal parts of the mandibular nerve appear to be ancestral and conservative and is critical to establishing a rational scheme of the relationships within and between the muscles supplied by the trigeminal nerve [9396]. Shimokawa and Akita have shown how we can use the precise trajectories of each named branch of the parts of the mandibular nerve to gain insights into the timelines of the differentiation of the mandibular and infrahyoid myoplates [11-14]. Oddly, Shimokawa's and Akita's recent papers do not refer to the subdivision of the main trunk of the mandibular nerve into its two trunks.

Warwick and Williams [1] write that "immediately beyond the junction of the two roots (sensory and motor), the (mandibular) nerve sends from its medial side its meningeal branch and the nerve to the medial pteygoid, and then divides into a smaller anterior and a large posterior trunk" in humans (p. 1007, our italics). Skinner and Aziz [96] have observed and discussed the phylogenetic basis of this important dichotomy of the mandibular nerve (see also [95]).

According to our observations, after its exit from the foramen ovale into the roof of the infratemporal fossa the human mandibular nerve may be divided as follows: 1) the main stump (branches: nervus spinosus; nerve to the medial pterygoid which give rise to the nerve branches to the tensor veli palatine and the tensor tympani); 2) the anterior trunk (branches: masseteric, posterior deep temporal, middle/accessory deep temporal nerves, the nerves to the lateral pterygoid heads and the buccal nerve); 3 ) the posterior trunk (branches: lingual, inferior alveolar, and the auriculotemporal nerves; the mylohyoid nerve is a branch of the inferior alveolar nerve). To gain insights into their migratory paths of the trigeminal muscles and their relative morphological, functional, ontogenetic and phylogenetic relationships to one another the elucidation of the branching pattern described above is crucial [11-14].
Shimokawa and Akita and their co-investigators have produced much-needed clarity and an evolutionary (and developmental) perspective to issues related to the classification of those masticatory muscles which are innervated by the branches of the anterior trunk of the mandibular nerve [11-14]. These muscles include the temporalis-masseter-lateral pterygoid muscle complex. Yet this provides us information only about part of the trigeminal nerve supplied muscles.

The principal objective of our paper is to describe the protocol by which the entire hemisected human mandible, its musculature, the mandibular nerve tree, and the maxillary vasculature may be detached en bloc. Although we did not secure the extraction of the tensor tympani, this is entirely achievable. Thus we can obtain the entire trigeminal musculature complex along with all of its osteological, and neurovascular associates without altering their topographical relationships or sectioning it into discontinous blocks. Our method allows us to empirically dissect the main stump of the mandibular nerve (and its branches), the anterior trunk of this nerve (and its branches) and the posterior trunk of this nerve (and its branches); the named motor nerves (and their branches) can be traced to the named muscles and to their subparts. The trajectories of the named nerves (and their branches) permits us to further test the predictions of Edgeworth [7], Shimokawa et al. [11, 12] and Akita et al. $[13,14]$.

Granted that no single anatomical trait exclusively and completely determines the status of the constituent intramuscular slips of each named muscle complex, nor the relationships of the individual complex to the other related complexes, the information gained from their nerve supplies provides significant clues to their affinities. Of course it is more persuasive to seek additional evidence, in addition to the conservative relations (e.g. nerves) of the muscles (or muscle parts), using several independent criteria, especially the evidence furnished by studies of comparative genetics, development, and phylogeny of the individual muscle complexes [5]. Nevertheless, nerves do provide powerful clues regarding muscle homology. Radinsky [4] writes that "similarity in nerve supply reflects similarity in pattern development. Hence nerve supply is a valuable criterion for determining muscle homology throughout the vertebrate classes". More pertinent to our paper is his added observation that "this principle ...is not so easy to apply in practice because of the branching and anastomoses of nerves and the difficulty of tracing fine branches". However, the application of proper methodology, especially the use of the dissecting microscope, has greatly increased our capacity to observe nerve branching between and within muscles with great accuracy $[9-14,33]$. There are further advantages to accurately mapping the nerves supplying the masticatory muscles. For example, Tomo et al. [10] carefully described and analyzed the nerve supply to the dog's pterygoid muscles to make a convincing case for the existence of a distinct, named branch to each pterygoid muscle as proposed by Edgeworth [7]. They also provided strong evidence showing that the singular canid lateral pterygoid represents the lower venter of the muscle we found in the primates; according to them the upper belly of the lateral pterygoid is absent in dogs. The detailed study of the nerve supply to the individual masticatory muscle complexes also helps to 
elucidate the relationships of their subparts. For example, Aziz et al. [33] and Akita et al. [13] described the nerve supply to the lateral pterygoid heads and independently concluded that their separation could not be deduced exclusively by a study of their nerve supply.

Lastly, the elucidation of the anatomical and functional relationships between the motor branches of the mandibular nerve and their muscles has important clinical applications as well. For instance, disturbances during the early morphogenesis of the mandibular branchial arch (usually in association with the second arch) gives rise to a recognizable, diagnostic constellation of otomandibular anomalies, including those of the mandibular muscles, which are derived from that source. Neonates with such defects exhibit facio-auriculo-vertebral spectrum (FAVS; Goldenhar Syndrome); although its etiology remains to be firmly established, Summitt [97] described a case which was familial i.e. due to genetic inheritance. Yet another practical clinical aspect of knowing the precise relationship of the branches of the mandibular nerve and their muscles involves the so-called compression (tunnel) syndromes. Many of these nerves pass through narrow clefts in and around the masticatory muscles and are prone to entrapment resulting in severe headache, muscular paresis, paraesthesia and compromised TMJ function [27, 98].

In the attempts to alleviate TMJ pain and tic douloureaux, anesthesiologists inject botox into selected masticatory muscles. The safe application of anesthesia in or around the infratemporal fossa requires a detailed knowledge of the layout of the mandibular nerve tree along with its associated musculature [99].

\section{CONCLUSIONS}

Burrows et al. [100] used the novel "masking" method to dissect and expose in exquisite detail the mimetic muscles of the chimpanzee. These investigations led them to conclude that contrary to previous claims, there are minimal anatomical differences between chimpanzees and humans, and idea corroborated by Diogo et al.'s recent comparative study of the facial muscles of primates [101]. Similarly, sophisticated methods are necessary to describe the details of the mandibular nerve tree and its associated muscles in humans [64].

The muscles supplied by the branches of the mandibular nerve play a crucial role in food ingestion and mastication, bolus formation, deglutition, communication (non-verbal and speech), oral respiration, and display, among others. Individually and collectively these functions are critical for the survival of our species. Phylogenetic and ontogenetic studies of the vertebrates show that the trigeminal musculature has a common history which is reflected in its osteology, arthrology, nerve and blood supply. The source of all these inter-related structures is the mandibular (or first) branchial arch. Standring [37] stated that the pharyngeal arches are also known as branchial arches because of their evolutionary origin supporting the gills in the earliest vertebrates and that many of the changes seen during development of the mammalian pharynx reflect the functional evolutionary origins of this region. Therefore, it can be argued that the mandibular arch (and its derivatives) represents a region under the control of a set of inter-related, and possibly linked, structural and regulatory genes that continue to be highly selected for as an interrelated complex.

In the absence of precise, detailed and comprehensive studies which chart the course of development of each of its components various schemes have been proposed to discern their ontogeny. Although the descriptions of the complex anatomy of each muscle in the trigeminal group continues to be refined, many questions regarding their precise ontogeny still remain to elucidated. However, the scheme based on the comparative anatomical studies proposed by Edgeworth [7, 8] has recently received confirmation and elaboration by analyses of the nerve supply to the muscles and by independent neurotopographical studies (using tracers) of the motor nucleus of the trigeminal nerve $[9-14,60,92]$. Nevertheless, these studies only provide a compartmentalized view of the whole system because of the difficulties in obtaining an integrated, interconnected block of all the components derived from the mandibular arch.

Finally, mandibular arch derivatives play a critical role in food processing (ingestion, mastication, bolus formation, etc.), communication (non-verbal and speech) and respiration (oral respiration and panting), among others. These have been critical in the survival and evolutionary development of the human species. It is very likely that the structural and regulatory genes which code for the mandibular arch derivatives are hereditarily linked in some manner and are passed down in human genealogy.

The method which we propose in this study precisely facilitates a complete exposition of the entire mandibular nerve tree and its connected muscles. Our method will facilitate the topographical mapping of each mandibular muscle and its component parts with reference to the mandibular nerve, its trunks and their branches. We hope that this will provide stronger tests of the hypothesis proposed by Edgeworth [7, 8], which has recently been questioned, in part, by Akita et al. [13]. Edgeworth [7, 8] proposed that the mandibular arch muscle plate diversified into a lateral and a medial component with reference to the mandibular nerve stump. The medial component forms the medial pterygoid, the tensor tympani and the tensor palate. The lateral anlage differentiates into the temporalis, the zygomaticomandibularis and the masseter. Edgeworth [8] wrote "the levator $\mathrm{m}$. externus developed into the pterygoideus externus, temporalis, zygomatico-mandibularis and masseter". Lubosch [89] suggested that the lateral pterygoid was phylogenetically related to the temporalis, and Tomo [9] and Tomo et al. [10] have concurred with this view.

Akita et al. [13, 14] have reexamined Edgeworth's hypothesis regarding the ontogeny and phylogeny of individual human masticatory muscles with a new set of observations which include the positional relationships of the muscles and their subparts in relation to their positions to each other and to specific parts of the mandibular nerve tree. They believe that such mapping reveals information about the ontogeny and phylogeny of these muscles. Akita et al. [13] write that in "1 specimen it was observed that the mandibular nerve trunk passed through the lower head of the lateral pterygoid. In addition, the nerve to the medial pterygoid sometimes formed a common trunk with the branch to the lower head; therefore, the mandibular nerve 
trunk may not serve as a clear demarcation between the medial and the lateral anlagen". They imply that the lateral pterygoid may be heterogenous in origin. However, this claim is based on isolated, single cases. Additional observations are necessary to test their claim. Their observations are based on a dissection protocol which uses the superior approach (Pinto's method [28]).

Although nerve-muscle specificity may provide strong augments regarding the relationship of muscle groups, it is best to test such claims with independent additional criteria. In fact, Edgeworth [7, 8] presented convincing arguments in favor of multifactorial analyses to establish muscle homologies, and this has been further stressed in Diogo \& Abadala's [102] recent review about the comparative anatomy, evolution, homologies and development of the head, neck, pectoral and forelimb muscles of vertebrates. The method which we have carefully described in the present paper thus provides a fresher way to analyse the trigeminal muscles and their nerves, and therefore to discuss the evolution and homologies of these structures, by using a more holistic, integrated and comprehensive approach.

\section{ACKNOWLEDGEMENTS}

This study was supported by funds from Howard University College of Dentistry, and the Department of Anatomy of the Howard University College of Medicine (James H. Baker, Ph.D., Chairman). We thank Mr. Greg Robertson (Photography), Ms. Lynette Thompson (Desktop Publishing), Mr. James Ferguson (Lab Assistance) and especially to Mr. Stafford Battle (Computer Graphics) for their contributions.

\section{REFERENCES}

[1] Warwick R, Williams PL. Gray's Anatomy. $35^{\text {th }}$ ed. Philadelphia: W.B. Saunders, Co 1973.

[2] Wilson-Pauwels L, Akesson EJ, Stewart PA. Cranial nerves anatomy and clinical comments. $1^{\text {st }}$ ed. Toronto: B.C. Decker, Inc 1988.

[3] Sadler TW. Langman's Medical Embryology. $10^{\text {th }}$ ed. Lippincott. Baltimore: Williams \& Wilkins 2006.

[4] Radinsky L. The comparative anatomy of the muscular system. In: Wake MH, Ed. Hyman's comparative vertebrate anatomy. $3^{\text {rd }}$ ed. Chicago: University of Chicago Press 1979; pp. 327-77.

[5] Diogo R, Abdala V, Lonergan N, Wood BA. From fish to modern humans - comparative anatomy, homologies and evolution of the head and neck musculature. J Anat 2008; 213: 319-424.

[6] Kardong KV. Vertebrates - Comparative anatomy, function, evolution. Oxford: WMC Brown Publ 1995.

[7] Edgeworth FH. On the development and morphology of the mandibular and hyoid muscles of mammals. Q J Microsc Sci 1914; 59: 573-645.

[8] Edgeworth FH. The cranial muscles of vertebrates. Cambridge: Cambridge University Press 1935.

[9] Tomo S. Morphological classification of the masticatory muscles based on their innervation. Ochanomizu Med J Tokyo 1990; 38: 57-71.

[10] Tomo S, Hirakawa T, Nakajima K, Tomo L, Kobayashi S. Morphological of the masticatory muscles in dogs based on their innervation. Ann Anat 1993; 175: 373-80.

[11] Shimokawa T, Akita K, Soma K, Sato T. Innervation analysis of the small muscle bundles attached to the temporalis muscles: truly new muscles or merely derivatives of the temporalis muscle? Surg Radiol Anat 1998; 20: 329-34.

[12] Shimokawa T, Akita K, Soma K, Sato T. An anatomical study of the muscles innervated by the masseteric nerve. Okajimas Folia Anat Jpn 1999; 59:251-64.

[13] Akita K, Shimokawa T, Sato T. 2000. Positional relationships between the masticatory muscles and their innervating nerves with special reference to the lateral pterygoid and the midmedial and discotemporal muscle bundles of temporalis. J Anat 1999; 197: 291-302.

[14] Akita K, Shimokawa T, Sato T. Aberrant muscle between the temporalis and the lateral pterygoid muscles: M. pterygoideus proprius (Henle). Clin Anat 2001; 14: 288-91

[15] Herring SW. Masticatory muscles and the skull: a comparative perspective. Arch Oral Biol 2007; 52:296-99.

[16] Gray H. Gray's anatomy. London: John W. Parker \& Son 1858

[17] Oberg S. Dissector for Netter's atlas of human anatomy. New Jersey: Ciba-Geigy Corp. Summit 1994; vol. 1.

[18] Clemente TD. Clemente's dissector. Baltimore: Lippincott Williams \& Wilkins 2002.

[19] Tank PW. Grant's dissector. $14^{\text {th }}$ ed. Baltimore: Wolters Kluwer/Lippincott Williams \& Wilkins 2009.

[20] Schumacher G-H. Funktionelle Morphologie der Kaumuskulatur. Jena: VEB Gustav Fischer Verlag 1961

[21] Schumacher G-H. Funktionsbedingter strukturwandel des M. masseter. Gegenbaurs Mosphol Jahrb 1962; 102: 150-69.

[22] Gaspard M, Laison F, Mailland M. organization architecturale et texture du muscle masséter chez les primates et l'homme. J Biol Bucc 1973a; 1: 7-20.

[23] Gaspard M, Laison F, Mailland M. Organization architecturale du muscle temporal et des faisceaux de transition, du complexe temporo-massétérin chez les Primates et l'Homme. J Biol Bucc 1973b; 1: 171-96.

[24] Naitoh R. Anatomical studies on the mandibular nerve. Shikwa Gakuho 1979; 79: 489-540.

[25] Terada S, Sato T. Nerve supply of the medial and lateral pterygoid muscles and its morphological significance. Okajimas Folia Anat Jpn 1982; 59: 251-64.

[26] Friedman MH. Anatomic relations of the medial aspect of the temporomandibular joint. J Prosthet Dent 1988; 59: 495-98.

[27] Loughner BA, Larkin MH, Mahan PE. Nerve entrapment in the lateral pterygoid muscle. Oral Surg Oral Med Pathol 1990; 69: 299306.

[28] Pinto OF. A new structure related to the temporomandibular joint and the middle ear. J Prosthet Dent 1962; 12: 95-103.

[29] Sugisaki M, Komori E, Nakazawa M, Tanabe H, Kato S Anatomical studies of the lateral pterygoid muscle by the superior approach and a review of the literature. Jpn J Oral Maxillofac Surg 1986; 32: 718-30.

[30] Abe S. Investigations of the run and the attachment of the lateral pterygoid muscle in Japanese. Shikwa Gakuho 1992; 92:1349-65.

[31] Pernkopf E. Atlas of topographical and applied human anatomy, head and neck. Philadelphia: W.B. Saunders, Co 1963; vol. 1.

[32] Kopf-Maier P. Wolf-Heidegger's atlas of human anatomy. Basel: Karger 1990; vol. 2.

[33] Aziz MA, Cowie RJ, Skinner CE, Mosaddad H. Complete pterygoidectomy - a novel method for the topographical investigation of the deep masticator space and it's contents. Clin Anat 2001; 14: 354-62.

[34] Schulman H. Vergleischende untersuchungen über die TrigeminusMuskalatur der Monotremen sowie die dabei in betracht kommenden nerven und knochen. Denkschr Med-nat Ges Jena 1908; 6: 297-400.

[35] Moore KL, Dalley AF. Clinically oriented anatomy. $5^{\text {th }}$ ed. Baltimore: Lippincott Williams \& Wilkins 2006.

[36] Drake RL, Vogl AW, Mitchell AWM. Gray's anatomy for students. $2^{\text {nd }}$ ed. Philadelphia: Churchill Livingstone 2010.

[37] Standring S. Gray's anatomy - the anatomical basis of clinical practice. $40^{\text {th }}$ ed. Philadelphia: Churchill Livingstone 2008.

[38] Wood WW. A review of masticatory muscle function. J Prosthet Dent 1987; 57: 222-32.

[39] Blanksma NG, van Eijden TMGJ. Electromyographic heterogeneity in the human temporalis muscle. J Dent Res 1990; 71: 47-52.

[40] Blanksma NG, Van Eijden TMGJ, Weijs WA. Electromyographic heterogeneity in the human masseter muscle. J Dent Res 1992; 71: 47-52.

[41] Ebert H. Morphologische und funktionelle Analyse des Musculus masseter. Zschr f Anat u Entwickl z Anat Entwickl 1939; 109: 790802.

[42] Schumacher G-H. Funktionelle muskel analysen. Zschr Med Labortechn Berl 1960; 1: 53-54. 
[43] Yoshikawa T, Suzuki T, Kuchi R, Matsuura H. The comparative anatomical study of the m. masseter of the mammal. Acta Anat Nippon 1961; 36:53-71.

[44] Yoshikawa T, Suzuki T, Kuchi R, Matsuura H. The lamination of the $\mathrm{m}$. masseter of the crab-eating monkey, orangutan and gorilla. Acta Anat Nippon 1962; 37: 206-17.

[45] Yoshikawa T, Suzuki T. The lamination of the human masseter the new identification of $\mathrm{m}$. temporalis superficialis, m.maxillomandibularis and $\mathrm{m}$. zygomatico-mandibularis in human anatomy. Acta Anat Nippon 1962; 37: 260-67.

[46] Yoshikawa T, Suzuki T. The comparative anatomical study of the masseter of the mammal, II. Okajimas Folia Anat Jap 1965; 40: 339-63.

[47] Yoshikawa T, Suzuki T. The anatomical study of the masseter of the mammal, III. Anat Anz 1969; 125S: 363-87.

[48] Schumacher G-H, Rehmer H. Über einege unterschiede am Kaupparat bei Lagomorphen und Rodentia. Anat Anz 1962; 111S: 103-22.

[49] Honèe GL. The anatomy of the lateral pterygoid muscle. Acta Morphol Neerl Scand 1972; 10: 331-340.

[50] Gaspard M, Laison F, Mailland M. Organization architecturale et texture des muscles ptérygoïdiens chez les primates superieurs. J Biol Bucc 1973c; 1: 215-33.

[51] Gaspard M, Laison F, Mailland M. Organization architecturale et texture des muscles ptérygoïdiens chez l'homme. J Biol Bucc 1973d; 1: 353-66.

[52] Grant PG. Lateral pterygoid: two muscles? Am J Anat 1973; 138: $1-10$.

[53] McNamara JA Jr. The independent functions of the two heads of the lateral pterygoid muscle. Am J Anat 1973; 138: 197-206.

[54] Juniper RP. The superior pterygoid muscle? Br J Oral Surg 1981; 19: 121-28.

[55] Mahan PE, Wilkinson TM, Gibbs CH, Mauderli A, Brannon LS. Superior and inferior-bellies of the lateral pterygoid muscle EMG activity at basic jaw positions. J Prosthet Dent 1983; 50: 710-18.

[56] Widmalm SE, Lillie JH, Ash MM Jr. Anatomical and electromyographic studies of the lateral pterygoid muscle. J Oral Rehabil 1987; 14: 429-46.

[57] McDevitt WE. Functional anatomy of the masticatory system. London: Wright 1989

[58] Hannam AG, McMillan AS. Internal organization in human jaw muscles. Crit Oral Biol Med 1994; 5: 55-89.

[59] Toldt C. Der Winkelfortsatz des Unterkiefers beim Menschen und bei den Säugertieren und die Beziehungen der Kaumuskeln zu demselben, Teil 2. Sitzungsber Math Naturwiss K1 1905; 113, Abt III: $344-76$.

[60] Göllner K. Untersuchungen uber die vom N. trigeminus innervierte Kiefermuskulatur des Schimpansen (Pan troglodytes, Blumenbach 1799 ) und des Gorilla (Gorilla gorilla gorilla, Savage and Wyman 1847). Gegenbaurs Morphol Jahrb 1982; 128: 851-903.

[61] Dunn GF, Hack GD, Robinson WL, Koritzer RT. Anatomical observation of a craniomandibular muscle originating from the skull base, the sphenomandibularis. J Craniomand Prac 1996; 14: 97-103.

[62] Türp JC, Cowley T, Stohler CS. Media hype: musculus sphenomandibularis. Acta Anat 1997; 158: 150-54

[63] White LW. The lateral pterygoid muscle: fact and fiction. J Clin Orthod 1985; 19: 584-87.

[64] Aziz MA, Cowie RJ, Skinner CE, Tsion SA, Gavin O. Are the two heads of the human lateral pterygoid separate muscles? A perspective based on their nerve supply. J Orofac Pain 1998; 12: 226-39.

[65] Klineberg I. The lateral pterygoid muscle: some anatomical physiological and clinical considerations. Ann R Aust Dent Surg 1991; 11:96-108

[66] Abe S, Takasaki I, Ichikawa K, Ide Y. Investigations of the run and the attachment of the lateral pterygoid muscle. Bull Tokyo Dent Coll 1993; 34: 135-39.

[67] Koritzer RT, Suarez F. Accessory medial pterygoid muscle. Acta Anat 1980; 107: 467-70.

[68] Couly G, Hureau J, Vaillant JM. Le complex dynamique du menisque temporo-mandibulaire. Rev Stomatol (Paris) 1975; 76: 597-605.

[69] Le Toux G, Duval JM, Darnault P. The human temporo-mandibular joint: current anatomic and physiological status. Surg Radiol Anat $1989 ; 11: 283-88$
[70] Meyenberg K, Kubik S, Palla S. Relationship of the muscles of mastification to the articular disc of the temporomandibular joint. Helv Odont Acta 1986; 30: 815-34.

[71] Myers LJ. Newly described muscle attachments to the anterior band of the articular disk of the temporomandibular joint. J Am Dent Assoc 1988; 117: 437-9.

[72] Merida-Velasco Jr, Rodriguez Vazquez JF, Jimenez Collado J. The relationships between the temporomandibular joint disc and related masticatory muscles in humans. J Oral Maxillofac Surg 1993; 51: 390-5.

[73] Barker BCW. The pterygoideus proprius muscle. Aust Dent J 1981; 36: 309-10.

[74] Nathan H. The pterygo-spinous muscle - an aberrant (atavic) remnant. Anat Anz 1989; 169: 97-9.

[75] Zenker W. Über die mediale Portion des M. temporalis und deren. Funktion. Öst Z Stomatol 1954; 51: 550-4.

[76] Shankland WE, Negulesco JA, O'Brien B. The "pre-anterior belly" of the temporalis muscle: a preliminary study of a newly-described muscle. J Craniomand Prac 1996; 14:106-12.

[77] Troiano MF. New concept of the insertion of the lateral pterygoid muscle. J Oral Surg 1967; 25: 337-40.

[78] Takano N. Anatomical and physiological studies on the human lateral pterygoid muscle. Shikwa Gakuho 1986; 86:933-69.

[79] Naohara H. The macroscopic and microscopic study of the human lateral pterygoid. Tsurumi Shigaku 1989; 15:1-26.

[80] Sümnig W, Bartolain G, Fanghänel J. Histological investigations of the morphological relationships between the lateral pterygoid muscle and the discus articularis in the human temporomandibular joint. Anat Anz Jena 1991; 173: 279-86.

[81] Heylings DJ, Nielsen IJ, McNeill C. Lateral pterygoid muscle and the temporomandibular disc. J Orofac Pain 1995; 9: 9-16.

[82] Filho A, Alves N. Insertion of the superior head of the lateral pterygoid muscle in the human fetuses. Int J Morphol 2007; 24 643-49.

[83] Ellenberger W, Baum H. Systematische und topographische anatomie des hundes. Berlin: Paul Parey 1891.

[84] Sisson S. A Textbook of veterinary anatomy. Philadelphia: Saunders Co 1910.

[85] Seiferle E. Lehrbuch der Anatomie der Haustiere Bd1. Berlin: Parey 1954.

[86] Luter A. Untersuchungen über die vom N. trigeminus innervierte Muskulatur der Selachier. Acta Soc Sci Finnicae 1909; 36:1-176.

[87] Luter A. Über die vom N. trigeminus vergsorgte Muskulatur der Amphibien mit einem vergleischenden Ausblick über den Adductor mandibulae der Gnatostomen usw. Acta Soc Sci Finnicae 1914; 44 $52-230$.

[88] Luter A, Lubosch W. Muskeln des Kopfes: Viscerale Muskulatur. In: Bolk L, Göppert E, Kallius E, Lubosch W, Eds. Handbuch der vergleischenden Anatomie der Wilbeltiere. Urban and Schwartzenberg Bd 5: Berlin und Wein 1938; pp. 467-42.

[89] Lubosch W. Neue Ergenbnisse in der Erforschung des Aufbaues der Trigeminusmukulatur. Verh physik-med Ges Würzburg NF 1918; 45: 181-6

[90] Lubosch W. Die Kaumuskeln der Teleosteer. Gegenbaurs Morphol Jahrb 1929; 61: 40-220.

[91] Lubosch W. Untersuchengen über die Visceralmuskulatur der Sauropsiden. Gegenbaurs Morphol Jahrb 1933; 72: 384-444.

[92] Tomo S, Nakajima K, Tomo I, Nodai E, Kobayashi S. The morphology and innervation of the lateral pterygoid muscle in the dog. J Anat 1995; 186: 435-39.

[93] Christensen K. The cranial nerves. In: Hartman CG, Straus WL, Eds. The anatomy of the rhesus monkey. Baltimore: Williams \& Wilkins 1933; pp. 290-306.

[94] Schwartz DJ, Huelke DF. The morphology of head and neck of the macaca monkey: the muscles of mastication and the mandibular division of the trigeminal nerve. J Dent Res 1963; 42: 1222-333.

[95] Nagashima S, Kang W-B, Hsiau C-H. The M. pterygoideus externus and M. pterygoideus internus in Formosa monkey. Acta Med Nagasaki 1975; 19: 1-11

[96] Skinner CE, Aziz MA. New methods of dissecting the masticator space of the rhesus macaque (Macaca mulatta). Primates 2003; 44 311-20.

[97] Summitt RL. Familial goldenhar syndrome. Birth Defects 1969; 5 106-20. 
[98] Shimokawa T, Akita K, Sato, T, Shuang-Qin Y, Tanaka S. Penetration of muscles by branches of the mandibular nerve: a possible cause of neuropathy. Clin Anat 2004; 17: 2-5.

[99] Brown DL. Atlas of Regional Anesthesia. $3^{\text {rd }}$ ed. Philadelphia: Saunders-Elsevier 2006

[100] Burrows AM, Waller BM, Parr LA, Bonar CJ. Muscles of facial expression in the chimpanzee (Pan troglodytes): descriptive, comparative and phylogenetic contexts. J Anat 2006; 208: 153-67.
[101] Diogo R, Wood BA, Aziz MA, Burrows A. On the origin, homologies and evolution of primate facial muscles, with particular focus on hominoids and a suggested unifying nomenclature for the facial muscles of the Mammalia. J Anat 2009; 215: 300-19.

[102] Diogo R, Abdala V. Muscles of vertebrates - comparative anatomy, evolution, homologies and development. Enfield, UK: Science Publishers 2010.

(C) Aziz et al.; Licensee Bentham Open

This is an open access article licensed under the terms of the Creative Commons Attribution Non-Commercial License (http://creativecommons.org/licenses/by-nc/ $3.0 /$ ) which permits unrestricted, non-commercial use, distribution and reproduction in any medium, provided the work is properly cited. 